\title{
The effects of trawling and primary production on size-structured food webs in seabed ecosystems
}

\author{
Leigh M. Howarth, Paul J. Somerfield, Julia L. Blanchard, James J. Waggitt, Susan Allender, \\ and Jan G. Hiddink
}

\begin{abstract}
Understanding how different drivers shape relationships between abundance and body mass (size spectra) is important for understanding trophic and competitive interactions in food webs and for predicting the effects of human pressures. Here, we sample seabed communities from small polychaetes $(<0.001 \mathrm{~g})$ to large fish $(>1 \mathrm{~kg})$ in the Celtic Sea and the western English Channel to examine how bottom trawling and primary production affect their size spectra and to compare these with predictions from a model that couples predator and detritivore communities. Size spectra were not well approximated by linear fits because of truncation of the size spectra of detritivores. Low primary production resulted in lower abundance of benthic fauna. Bottom trawling reduced the abundance of predators and large detritivores but allowed small detritivores to increase in abundance. These empirical size spectra were partly consistent with predictions from the size spectra model, showing that understanding the structuring of benthic communities requires a consideration of both size and functional group. The findings highlight the need for an ecosystem approach to understanding the effects of exploitation and climate change on marine ecosystems.

Résumé : La compréhension de l'incidence de différents facteurs sur les relations entre l'abondance et la masse corporelle (spectres de tailles) est importante pour bien comprendre les interactions trophiques et concurrentielles au sein des réseaux trophiques et pour prédire les effets des pressions d'origine humaine. Nous échantillonnons des communautés du fond marin allant de petits polychètes $(<0,001 \mathrm{~g})$ à de grands poissons $(>1 \mathrm{~kg})$ dans la mer Celte et la Manche occidentale, afin d'examiner l'incidence du chalutage de fond et de la production primaire sur leurs spectres de tailles et de comparer ces derniers aux prédictions d'un modèle qui jumelle les communautés de prédateurs et de détritivores. Les spectres de tailles ne sont pas bien approximés par des fonctions linéaires en raison de la troncation des spectres de tailles des détritivores. Une faible production primaire se traduit par une plus faible abondance de la faune benthique. Le chalutage de fond réduit l'abondance des prédateurs et des grands détritivores, mais permet une augmentation de l'abondance des petits détritivores. Ces spectres de tailles empiriques concordent en partie avec des prédictions tirées du modèle de spectres de tailles, ce qui démontre que la compréhension de la structuration des communautés benthiques nécessite la prise en considération de la taille et du groupe fonctionnel. Ces résultats mettent en relief la nécessité d'une approche écosystémique pour comprendre les effets de l'exploitation et des changements climatiques sur les écosystèmes marins. [Traduit par la Rédaction]
\end{abstract}

\section{Introduction}

Marine ecosystems are subject to a range of anthropogenic pressures, many of which are increasing in intensity and occurrence (Lotze et al. 2006; Poloczanska et al. 2013). Two important pressures on marine ecosystems are fishing and changes in primary production due to climate change and eutrophication. High levels of fishing pressure can truncate age and size distributions of target and nontarget species, drive shifts in maturation to earlier ages and sizes, and remove large predators, which can cause communities to exhibit steeper size spectrum slopes than those exposed to lower fishing intensities (e.g., Daan et al. 2005; Queirós et al. 2006). Changes in primary production can result from eutrophication and might result from climate change (Behrenfeld et al. 2016; Behrenfeld et al. 2006). High levels of primary production can increase rates of growth and biomass accumulation, raising size spectral intercepts (Jennings and Blanchard 2004; e.g., Macpherson et al. 2002). These drivers rarely operate in isolation, and their interactions can generate unexpected ecological responses (Crain et al. 2008). For example, a recent study found that higher levels of primary production make benthic ecosystems more resilient to bottom trawling impacts (Hiddink et al. 2017) and that the effects of bottom trawling on the trait composition of benthos are greater in areas of high primary production (Howarth et al. 2018b). Hence, there is a need to better understand how marine ecosystems react to multiple drivers (Fu et al. 2018).

The body size distributions of aquatic communities are governed by fundamental ecological principles. In aquatic ecosystems, most predators are larger than their prey because they are unable to consume organisms larger than themselves (Jennings et al. 2002b; Law et al. 2009). This, in combination with higher population growth rates at the base of food webs and inefficient energy transfer between trophic levels, is why large organisms are much rarer within the aquatic environment than small ones (Sprules et al. 2016). A size spectrum characterizes the size distribution of all individuals in an ecosystem according to biomass across size classes. When plotted as a frequency distribution of

Received 20 January 2020. Accepted 6 June 2020.

L.M. Howarth, J.J. Waggitt, S. Allender, and J.G. Hiddink. Bangor University, School of Ocean Sciences, Menai Bridge, LL59 5AB, UK.

P.J. Somerfield. Plymouth Marine Laboratory, Prospect Place, Plymouth, PL1 3DH, UK.

J.L. Blanchard. Institute for Marine and Antarctic Studies, University of Tasmania, Hobart, TAS 7001, Australia.

Corresponding author: Jan G. Hiddink (email: j.hiddink@bangor.ac.uk).

Copyright remains with the author(s) or their institution(s). Permission for reuse (free in most cases) can be obtained from copyright.com. 
log abundance versus log body size, these "size spectra" typically have negative slopes close to -1 , which emerge from the predatory, competitive, and feeding interactions within ecosystems (Blanchard et al. 2009). This negative slope is a macroecological phenomenon that exhibits remarkable regularity among different types of organisms and habitats (Gómez-Canchong et al. 2013; Macpherson et al. 2002). Various models describe how community size spectra arise from individual-level, size-based processes (Blanchard et al. 2017). The simplest of these aggregate all individuals within a single size spectrum regardless of their feeding strategy. However, recent evidence suggests this is too simplistic, as organisms with different trophic positions (e.g., detritivores and predators) are expected to exhibit different size spectra and different responses to pressures. Theory predicts that when food availability falls with body size (as in most aquatic food webs where larger predators eat smaller prey), the size spectrum slope is steeper than when organisms of different sizes compete for a shared unstructured resource (e.g., autotrophs, herbivores, and detritivores; hereinafter dubbed "detritivores"; Blanchard et al. 2009).

Blanchard et al. (2009) constructed a size spectrum model that described the feeding interactions between predators and benthic detritivores. Their simplest models were "uncoupled" and assumed that neither feeding group affected another. In contrast, "coupled" models were more complex and assumed that predators fed on a range of smaller-sized prey, which included detritivores, while detritivores fed on a non-size-structured food pool of detritus. This model predicted that detritivores have shallower, but truncated (with a steeper slope at larger body sizes), size spectral slopes compared with predators and that predator slopes steepen in response to fishing pressure. Detritivore truncation started at $1 \mathrm{~g}$ when coupled with predation and at $100 \mathrm{~g}$ without coupling due to senescence of detritivores. In contrast, fishing was predicted to release detritivores from their predators, resulting in greater abundances of large detritivores and a shallowing of their size spectral slopes. Even though there is clear evidence that bottom trawling affects benthic invertebrates (Sciberras et al. 2018), there is debate about how important this effect is relative to predation release (van Denderen et al. 2013). The Blanchard et al. (2009) model assumed fishing has no direct effect on predators $<10 \mathrm{~g}$ and no direct effect on detritivores. Hence, fishing could only affect detritivores through competition release. High levels of primary production were predicted to provide more energy to the ecosystem, supporting faster growth rates and larger body sizes in both groups, resulting in higher size spectra intercepts and shallower slopes. Conversely, low levels of primary production provided less energy, reducing the abundance of large body sizes and steepening slopes. To date, no rigorous empirical test of these predictions has been carried out.

To improve our understanding of how multiple drivers and predator-prey interactions shape size spectra and affect food web dynamics, we test the prediction of the "coupled" model in Blanchard et al. (2009) with empirical observations. By sampling benthic predators and detritivores in the Irish and Celtic seas and the western English Channel across gradients of bottom trawling pressure and primary production, we test the following hypotheses:

H1. The size spectrum slope of detritivores is shallower than that of predators, because detritivores share a common unstructured food source, while predators eat prey smaller than themselves, and food availability falls with body size because of energy loss in trophic transfers. The detritivore size spectrum will be truncated at larger sizes $(>1 \mathrm{~g})$ because detritivores experience predation pressure (Fig. 1A sketches the hypothesis).

H2. Higher levels of primary production will provide more energy to the ecosystem, supporting faster growth rates and larger body sizes in both groups, resulting in higher intercepts and shal-
Fig. 1. Hypothesized size spectra for hypotheses 1,2 , and 3. (A) $\log _{10}$-normalized size spectra of the benthic community for the two feeding strategies. (B) $\log _{10}$-normalized size spectra of the benthic community for the two feeding strategies for different levels of primary production (PP). (C) $\log _{10}$-normalized size spectra of the benthic community for the two feeding strategies for different levels of bottom trawling effort (BT). [Colour online.]

\section{A. Hypothesis 1}
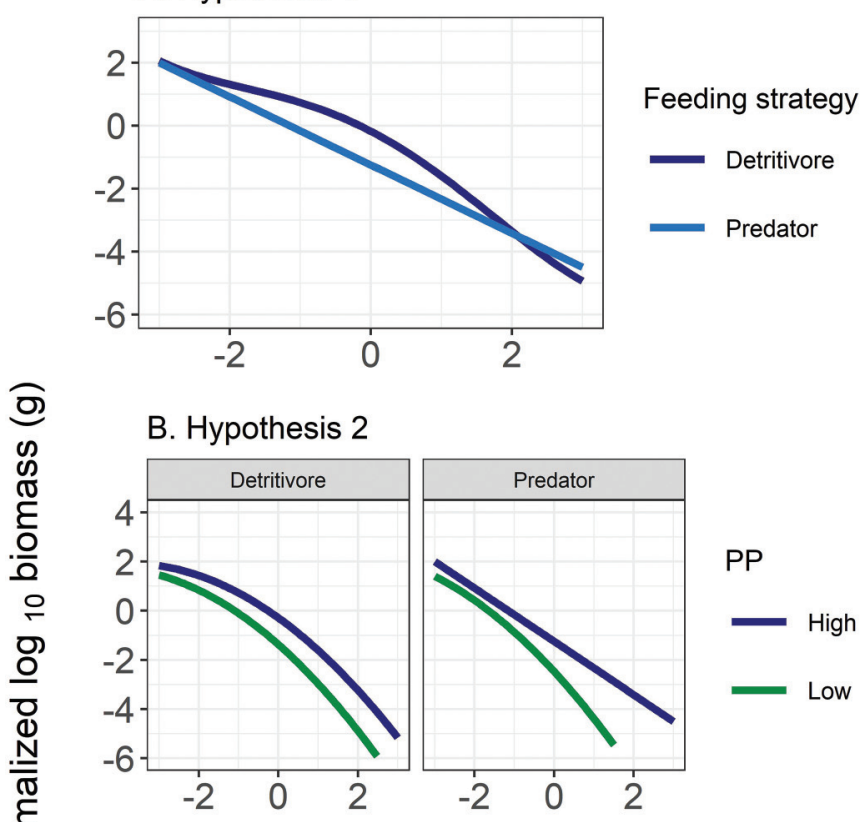

C. Hypothesis 3

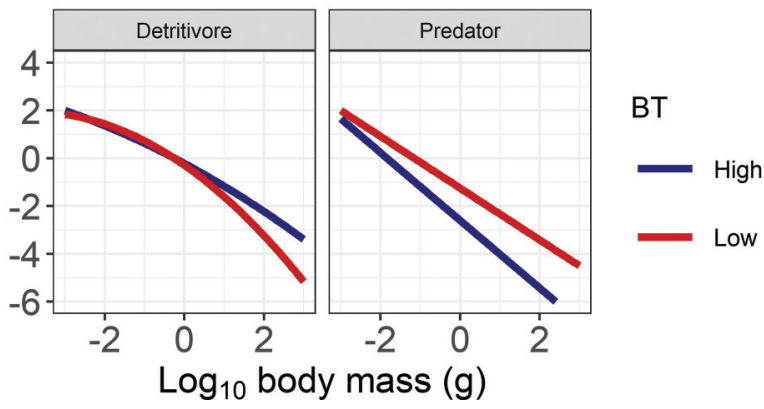

lower slopes. Low levels of primary production will not provide enough energy to support a full range of sizes, so size spectra in the predator communities will be truncated, with relatively steep slopes (Fig. 1B).

H3. Bottom trawling will result in steeper size spectral slopes in predators because larger predators are caught and removed (e.g., Nilssen et al. 1986). This will release detritivores from their predators, resulting in greater abundance of large detritivores and therefore a shallowing of detritivores' size spectral slopes (Fig. 1C).

\section{Methods}

Here we examine normalized size spectra. A normalized size spectrum converts the biomasses or abundances to densities by dividing them by the width of the size classes (Blanchard et al. 2017). The intercept and the slope of the size spectrum characterize the total abundance in the community and its rate of decrease with body size. We use the terms "slope", "intercept", and "abundance" to describe patterns in the size spectra in this paper. The "slope" is the slope of the fit through the data of a particular 
Fig. 2. Sampling stations in the study area in southwest of the United Kingdom. Each point represents a $1 \times 0.6 \mathrm{nautical}$ mile box $(1 \mathrm{n} . \mathrm{mi}$. $=$ $1.852 \mathrm{~km})$, the shade and size of which signifies the level of primary production $\left(\mathrm{mg} \mathrm{C}^{-2} \mathrm{~m}^{-2} \cdot \mathrm{year}^{-1}\right)$ and trawling intensity (year $\left.{ }^{-1}\right)$. Map produced using R 3.5.3 (R Development Core Team 2011). Sources are as follows: base map: European Environment Agency (2015); primary production: MODIS satellite sensor provided by Natural Environment Research Council Earth Observation Data Acquisition and Analysis Service (NEODAAS); see Howarth et al. (2018b); trawling intensity: Eigaard et al. (2017); see Howarth et al. (2018b). [Colour online.]

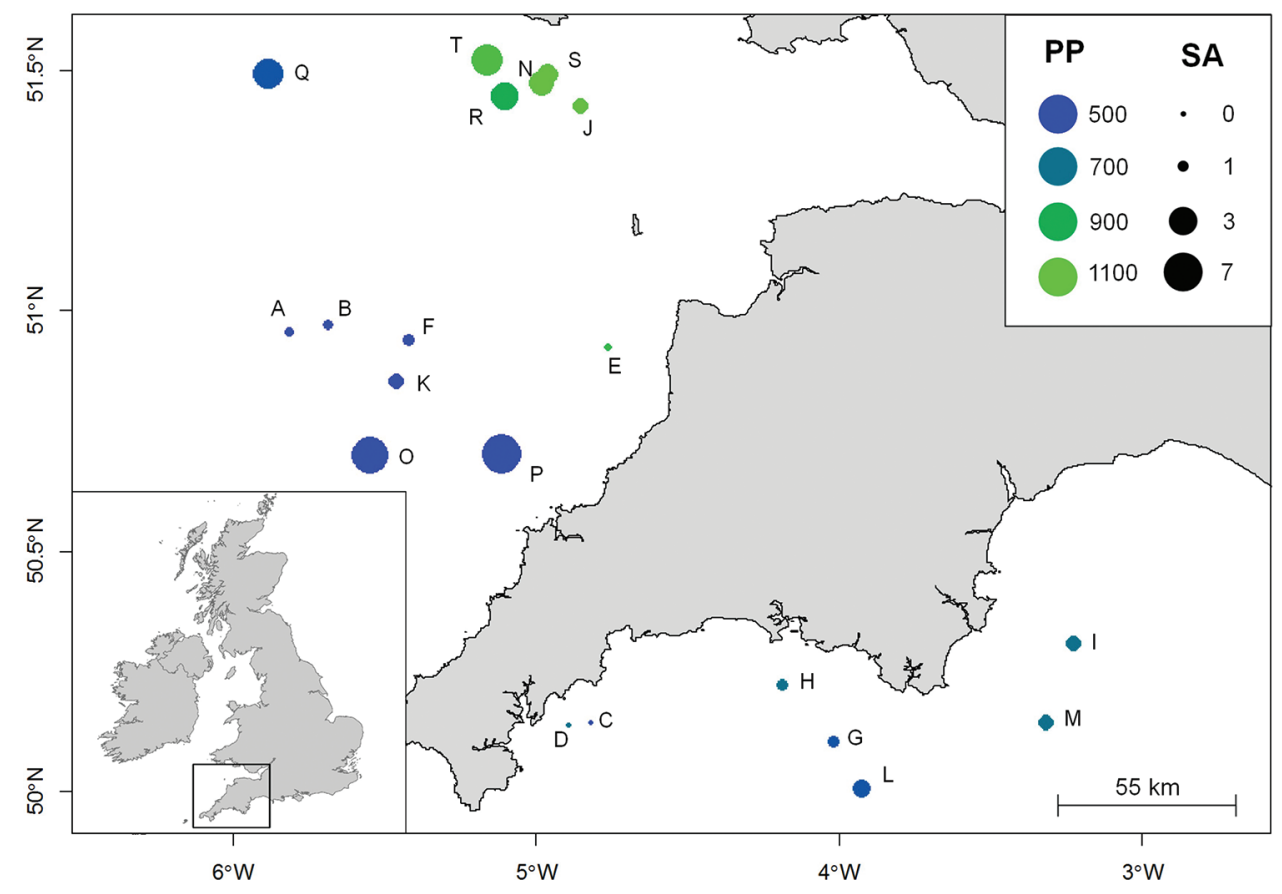

Table 1. The range of values that defined the four experimental treatments of trawling intensity (quantified as the swept area ratio, SAR) and primary productivity (PP) sampled in this study and that were used for plotting intensity levels in Figs. 3-5.

\begin{tabular}{|c|c|c|}
\hline Treatment & SAR (year-1) & PP $\left(\mathrm{mg} \mathrm{C} \cdot \mathrm{m}^{-2} \cdot\right.$ year $\left.^{-1}\right)$ \\
\hline 1. Low & $0<$ SAR $<0.4$ & $0<\mathrm{PP}<550$ \\
\hline 2. Medium low & $0.4<$ SAR $<1.4$ & $550<\mathrm{PP}<775$ \\
\hline 3. Medium high & $1.4<$ SAR $<5$ & $775<\mathrm{PP}<1000$ \\
\hline 4. High & $5<$ SAR $<15$ & $1000<\mathrm{PP}<1500$ \\
\hline
\end{tabular}

section of the size spectrum. The intercept is defined here as the point where the size spectrum starts, at $\log _{10}$ body mass $=-3$.

\section{Sampling}

This study analyses a dataset described by Howarth et al. (2018b) and available from Howarth et al. (2018a). In brief, trawling intensity (quantified as the swept area ratio, SAR (year-1), from vessel monitoring systems data) and primary production (PP, $\mathrm{mg} \mathrm{C} \cdot \mathrm{m}^{-2}$.year ${ }^{-1}$, estimated by the MODIS satellite sensor) for the United Kingdom were divided into four categories (divided at equal intervals on a log scale for trawling intensities and equal intervals on a natural scale for PP; Table 1). Sampling stations were then chosen in the Irish Sea, Celtic Sea, and western English Channel to cover all combinations of the four levels of trawling intensity and primary production on areas of seabed with similar sediments and depths (sand and muddy sand with moderate shear bed stress between 40 and $100 \mathrm{~m}$ depth; http://jncc.defra.gov.uk/ ukseamap). Twenty stations were sampled in September 2015 and again in April 2016 (Fig. 2). A retrospective multivariate analysis of the environmental variables at the sampling stations indicated that the environmental conditions at two stations were dissimilar to the others based on their sediment particle size distribution (with very low and very high mean sediment particle sizes, respectively). These were excluded from further analyses (details in
Howarth et al. 2018b). Hence, data are missing for the combination of low trawling and moderately high primary production. Three different sampling gears were deployed at each station to ensure a large size range of the benthic community (small invertebrates to demersal fish) was captured. Day grabs primarily sampled infauna and very small epifauna, $2 \mathrm{~m}$ beam trawls primarily sampled large infauna and epifaunal organisms, and $4 \mathrm{~m}$ beam trawls primarily sampled larger epifauna and fish. All organisms caught were identified to at least family level (often to species), counted, and wet-weighed.

The scaled abundance and biomass were used to create $\log _{10^{-}}$ normalized biomass size spectra by aggregating individual body masses into $\log _{10}$ bins. A normalized size spectrum converts the biomasses to densities by dividing them by the width of the body mass classes (Sprules et al. 2016). Abundance and biomass values for the $2 \mathrm{~m}$ and $4 \mathrm{~m}$ beam trawls were scaled to account for differences in sampling area and efficiency compared with the Day grab (for which we assumed $100 \%$ of the fauna from $0.1 \mathrm{~m}^{2}$ was collected) as described in Howarth et al. (2018b). The scaling assumed that $\log _{10}$-normalized biomass in the body mass categories that overlap between the sampling gears are continuous. Biomasses from the $2 \mathrm{~m}$ beam trawl were scaled so that the $\log _{10^{-}}$ normalized biomass per body mass category in the overlapping body mass categories matched the Day grab $\log _{10}$-normalized biomass per body mass category. Subsequently, biomasses from the $4 \mathrm{~m}$ beam trawl were scaled so that the $\log _{10}$-normalized biomass per body mass category in the overlapping body mass categories matched the (previously scaled) $2 \mathrm{~m}$ beam trawl $\log _{10}$-normalized biomass per body mass category. For a more detailed description of these methods, see the "Gear calibrations" section and supplementary material of Howarth et al. (2018b).

Predators are defined here as animals that obtain most of their food by eating and killing whole living organisms. Detritivores are defined as animals that obtain most of their food from plants or detritus (dead organic material), and the group therefore includes herbivores and detritivores (see the online Supplementary Mate- 
Table 2. Generalized additive mixed model (GAMM) outputs for statistical comparison of different models.

\begin{tabular}{llrrll}
\hline \multicolumn{2}{l}{ Model } & \multicolumn{1}{c}{ AIC } & \multicolumn{1}{c}{$\Delta_{i}$} & $w_{i}$ & Test of: \\
\hline 1 & te $\left(\log _{10}\right.$ class $)$ & 1054.9 & 321.6 & 0 & - \\
2 & te $\left(\log _{10}\right.$ class, by = FS $)$ & 786.6 & 53.2 & 0 & - \\
3 & te $\left(\log _{10}\right.$ class, BT, by = FS $)$ & 766.1 & 32.8 & 0 & H2 \\
4 & te $\left(\log _{10}\right.$ class, PP, by = FS $)$ & 770.6 & 37.3 & 0 & H3 \\
5 & te $\left(\log _{10}\right.$ class, BT, PP) & 1053.5 & 320.1 & 0 & H1 \\
6 & te $\left(\log _{10}\right.$ class, BT, PP, by = FS $)$ & 733.4 & 0.0 & 1 & - \\
\hline
\end{tabular}

Note: Response variable $=\log _{10}$-normalized biomass; $\mathrm{PP}=$ primary production ( $\mathrm{mg} \mathrm{C} \cdot \mathrm{m}^{-2}$.year $\left.{ }^{-1}\right) ; \mathrm{BT}=$ bottom trawling (swept area ratio, year $\left.{ }^{-1}\right) ; \mathrm{FS}=$ feeding strategy: predators or detritivores; "by" in the tensor product specifies the interaction between the feeding strategy and the other explanatory variables. The "te" function in mgcr package in $\mathrm{R}$ produces a full tensor product smooth. Comparison of the AIC in the column "Test of" with model 6 provides a test of the hypothesis in that column. $\Delta_{i}$ is differences in AIC values between each model and the most parsimonious model (model 6). $w_{i}$ are Akaike weights and represent weight of evidence (out of 1.00) that each model is the best model in the set.

rial; Table S1 lists all the classification for all taxa encountered ${ }^{1}$ ). Our definition of detritivores and predators is more refined than that of Blanchard et al. (2009), where all grab-collected animals were defined as detritivores and all trawl-caught animals as predators.

\section{Analysis}

Because our hypotheses assume nonlinear patterns in size spectra (e.g., truncation), linear models were not considered a suitable approximation, especially because nonlinearity makes the range of body sizes over which the slope and intercept are fitted very important. We therefore fitted a generalized additive mixed model (GAMM) using the gamm function in the package mgcv in $\mathrm{R}$ (Wood 2015) to examine the effects of trawling, primary production, and feeding strategy on benthic size spectra. Sampling station was included as a random effect because the measurements for the different size classes are not independent. The response variable is the $\log _{10}$-normalized biomass per body mass category. We fitted and compared GAMMs to test the different hypotheses (Table 2). Interactions were specified using the te function in $\mathrm{mgcv}$ that produces a full tensor product smooth. To make the interpretation of the results easier, we plotted $\mathrm{H} 1$ and $\mathrm{H} 2$ predictions using only low fishing effort stations ( $\mathrm{SAR}<1.4$ year $^{-1}$ ), while H3 predictions were plotted for intermediate PP stations (550-1000 $\mathrm{mg} \mathrm{C}^{-2} \mathrm{~m}^{-2} \cdot \mathrm{year}^{-1}$ ).

Because the normalized biomass is $\log _{10}$-transformed, size classes without biota resulted in undefined data, which can result in an underestimation of the steepness of size spectra. To avoid this, we replaced the normalized biomass for size classes without biota by a very small value, calculated as 0.5 times the lowest nonzero value in that size class. A sensitivity analysis showed that the results and conclusion were not affected by the replacement value chosen.

Although the survey design used categorizations of bottom trawling intensity and primary production levels, statistical analyses used them as continuous variables for greater power and more accurate estimation of effects. For ease of plotting, however, the fitted values generated by the statistical models were plotted against $\log _{10}$ size class and plotted between the categorical levels of fishing pressure and primary production (even though the model fitted them as continuous variables).

\section{Results}

Combining samples from three different sampling gears resulted in continuous size spectra with $\log _{10}$ body mass classes spanning six orders of magnitude from small worms $<1 \mathrm{mg}$ to
Fig. 3. $\log _{10}$-normalized size spectra of the benthic community for the two feeding strategies, for stations with low bottom trawling effort (testing H1). Points show $\log _{10}$-normalized biomass per $0.5 \mathrm{~m}^{2}$ for each size class for each station, and lines and shaded areas represent the fitted generalized additive mixed model (GAMM) and their $95 \%$ confidence intervals. [Colour online.]

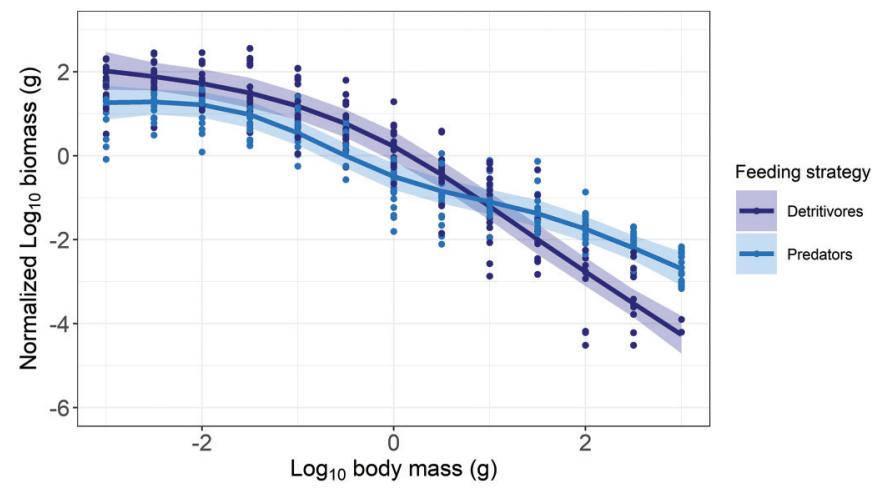

large fish $>1 \mathrm{~kg}$. The recorded size spectra had some distinct deviations from a straight line, in particular for detritivores, and would have therefore been poorly described by simply estimating their intercepts and slopes from linear fits.

The AIC of the GAMM that used PP, bottom trawling intensity, and feeding strategy as explanatory variables was lower than that of models that omitted one or more of these variables (model 6 in Table 2; $R^{2}=0.931, n=464$; Fig. $S 1^{1}$ ), indicating that each of these variables increased the explanatory power of the model. This full model is therefore used to infer and plot relationships below.

Detritivores were more abundant than predators at body masses $<3 \mathrm{~g}$, and predators were more abundant than detritivores at sizes $>10 \mathrm{~g}$ (H1; Fig. 3; Table 2). The detritivore size spectrum slope became steeper (more negative) at $\log _{10}$ body mass $>0(1 \mathrm{~g})$, while the slope for predators was more constant, suggesting that predation depresses and truncates the abundance of large detritivores. The size spectrum slope for detritivores is therefore similar to that of predators at small body sizes and steeper at large body sizes. The AIC of the model including feeding strategy was much lower than a model that did not include it ( $\triangle$ AIC of model 6 versus model 5 = 331.4; Table 2).

The size spectral intercepts were higher at higher PP for small detritivores, but detritivore size spectra converged at large body sizes, making the size spectral slopes somewhat steeper at high PP (H2; Fig. 4; Table 2). For predators, the size spectra had the lowest intercept at the lowest PP, but there was no clear differentiation among the other levels of PP. No truncation of the predator size spectrum was evident at low PP. The AIC of the model that included PP was lower than a model that did not include it ( $\triangle \mathrm{AIC}$ of model 6 versus model $3=59.4$; Table 2 ).

Bottom trawling effort did not affect predator slopes, but the size spectrum was lower over most of the range of body sizes for predators at higher fishing effort (H3; Fig. 5; Table 2). Small detritivores were more abundant, while large detritivores were less abundant, at high trawling effort. The AIC of the model that included trawling effort was lower than a model that did not include it ( $\triangle$ AIC of model 6 versus model $4=49.2$; Table 2 ).

\section{Discussion}

This study investigated the effects of bottom trawling and primary production on the size spectra of temperate seabed communities, over six orders of magnitude of body mass. Ours is one of the first studies to empirically compare size spectra between func-

${ }^{1}$ Supplementary data are available with the article through the journal Web site at http://nrcresearchpress.com/doi/supp1/10.1139/cjfas-2020-0025. 
Fig. 4. $\log _{10}$-normalized size spectra of the benthic community for the two feeding strategies for different levels of primary production (PP; see Table 1 for category levels), for areas with low bottom trawling effort (testing H2). Points show the mean $\log _{10}$-normalized biomass per $0.5 \mathrm{~m}^{2}$ for each size class over all stations, and lines and shaded areas represent the fitted GAMM and their 95\% confidence intervals. [Colour online.]

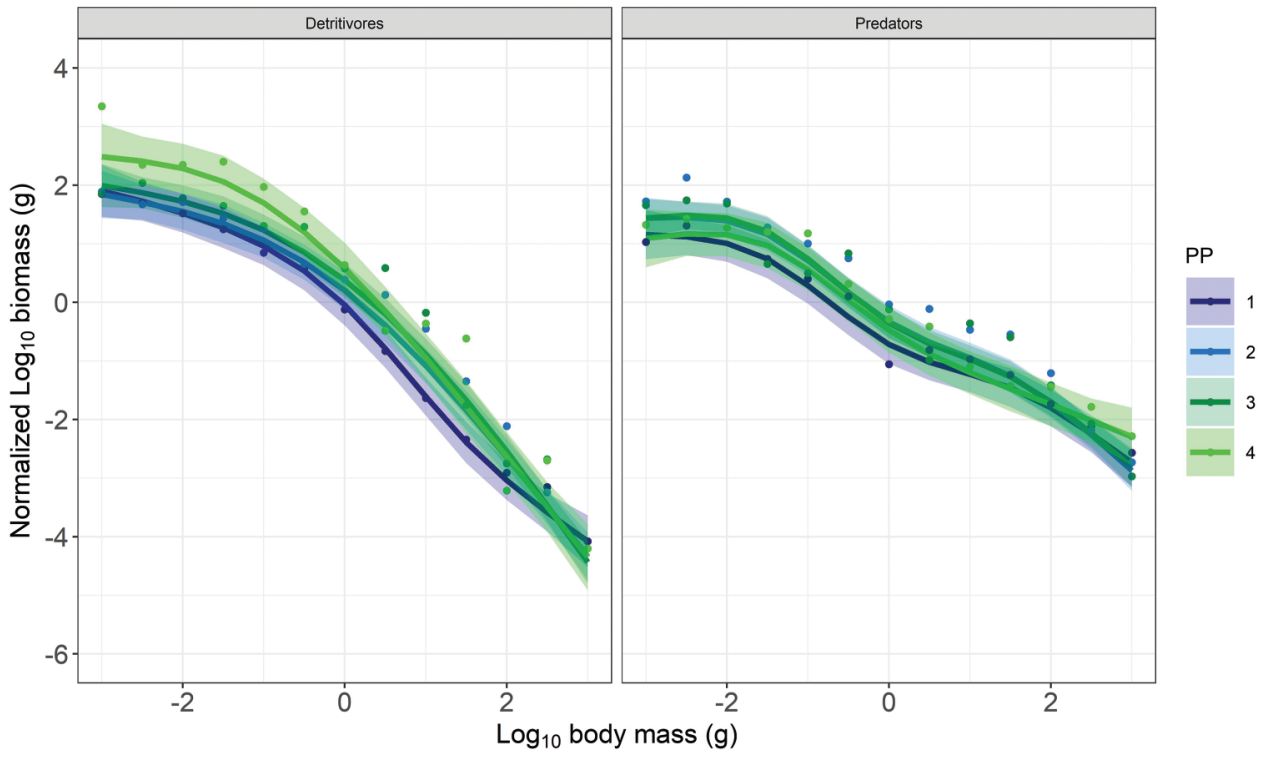

Fig. 5. $\log _{10}$-normalized size spectra of the benthic community for the two feeding strategies for different levels of bottom trawling effort (BT; see Table 1 for category levels), for areas with intermediate primary production (testing H3). Points show the mean over all stations $\log _{10}{ }^{-}$ normalized biomass per $0.5 \mathrm{~m}^{2}$ for each size class, and lines and shaded areas represent the fitted GAMM and their confidence intervals. [Colour online.]

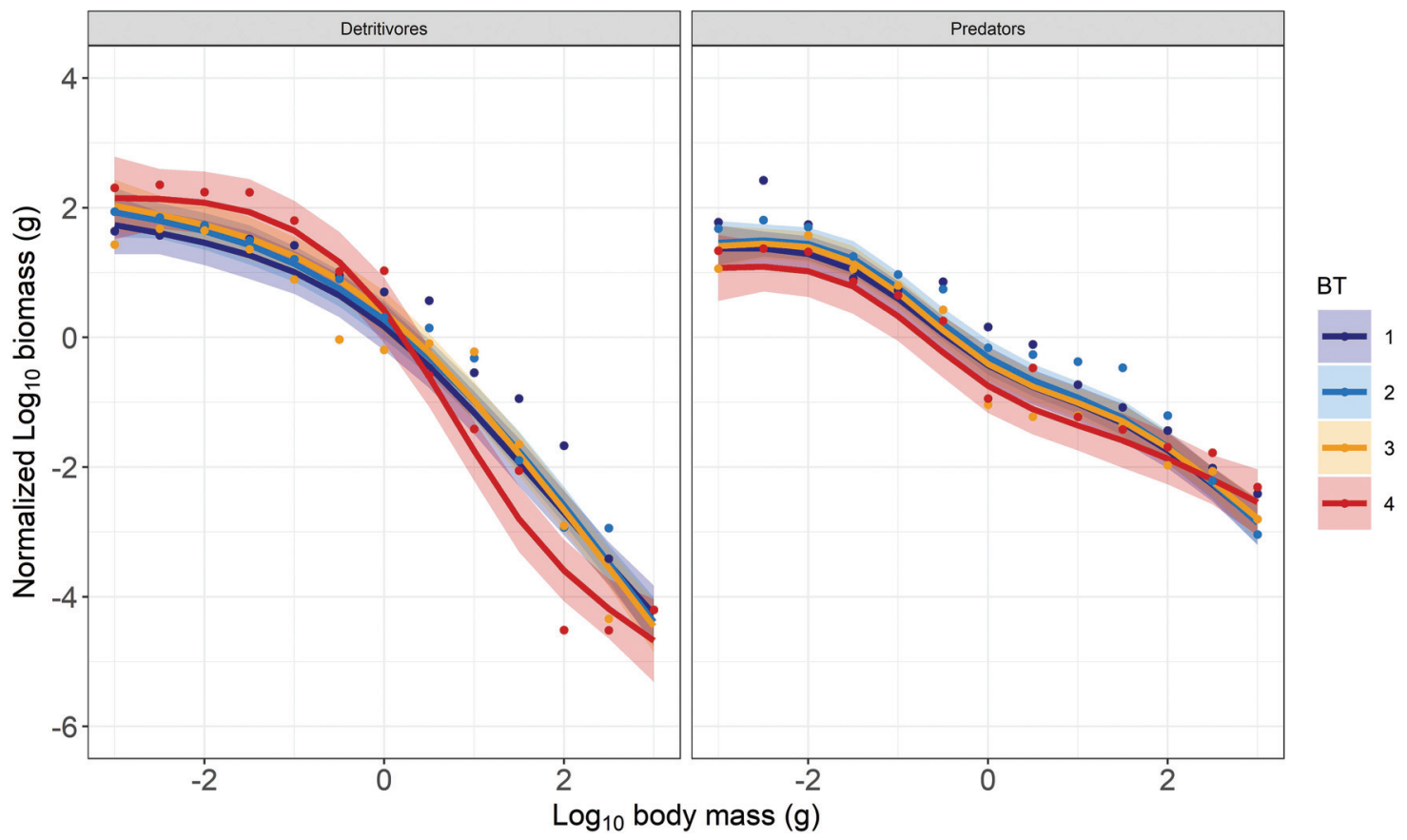

tional groups (Blanchard et al. 2017; Blanchard et al. 2009; Robinson et al. 2016), and it shows that distinguishing between the two feeding strategies improves our ability to understand how food web dynamics translate into size spectra. Our results show that normalized benthic size spectra are not well approximated by linear fits because of truncation in the size spectra of detritivores.

Our first hypothesis (H1: the slopes of detritivores size spectra would be shallower than those of predators because detritivores share common food sources, while predation is size-structured) was not supported by the results. We discuss possible reasons for this further below. The second part of $\mathrm{H} 1$, that the detritivores size spectrum is truncated at large sizes because detritivores experience predation pressure, was supported. The comparison of coupled (where predators eat detritivores) and uncoupled (where they do not) models in Blanchard et al. (2009) showed that the body mass at which the truncation begins is driven by the existence of predation on detritivores, beginning at $1 \mathrm{~g}$ with predation in coupled models and at $100 \mathrm{~g}$ in uncoupled models due to senescence of detritivores. Our results based on empirical data show that the 
truncation starts around $1 \mathrm{~g}$, indicating that top-down effects of predation on detritivores strongly affect their size spectra. That predatory feeding strategies can support larger body sizes than detritivory is supported by fundamental ecological theory (Elton 1927; Sheldon and Kerr 1972) and empirical studies (Jennings and Mackinson 2003; Jennings and Blanchard 2004; Jennings et al. 2001), both of which suggest that trophic level generally increases with body size. This is because predators tend to ingest prey smaller than themselves and that large organisms feeding at low trophic levels (e.g., baleen whales) are rare (Blanchard et al. 2017; Cohen et al. 1993). Overall, the coupled model predictions were largely consistent with our empirical data, highlighting the importance of predator-detritivore coupling in food web dynamics. These results therefore show that an understanding of the structuring of benthic communities requires a consideration of both size and functionality.

Higher levels of primary production should equate to greater quantities of phytoplankton, detritus, and other organic matter sinking towards the seafloor (Blanchard et al. 2009). In turn, this should result in greater abundances of detritivores and provide more prey to the predator community and may be why predator size spectra were higher in areas with higher primary production. Conversely, areas with less available energy should be less able to support large body sizes, making the slopes of size spectra more negative as predicted by models (Blanchard et al. 2009). Our second hypothesis (H2: high levels of primary production would result in higher size spectral intercepts and shallower slopes by providing more energy to the ecosystem, which should support faster growth rates and larger body sizes) was only partly supported. The intercepts of the size spectra were lower at lower PP for both detritivores and predators, but no shallowing of the slopes was evident. In fact, the slope for detritivores was steeper at high PP. The second part of $\mathrm{H} 2$, that the predator size spectrum is truncated at large sizes because at low levels of primary production there is not enough energy to support a full range of sizes, was not supported by the results. These findings suggest that although higher PP can support a higher standing stock of benthic invertebrates, the lack of shallower size spectra slopes shows that it does not result in a faster growth of benthic biota, contrary to expectations (Sprules and Munawar 1986). Our understanding of the strength of competition over resources in soft-sediment benthic invertebrates is very limited (Branch 1984; Wilson 1990), but these results suggest that the increase in standing stock (represented by the higher intercept) has increased competition over resources among the benthos, to a level where the same amount of resources are available per unit benthic biomass as at lower PP.

Our third hypothesis (H3) was that bottom trawling will result in steeper size spectral slopes in predators because they are caught at larger sizes, and this will release detritivores from predation, resulting in greater abundance of large detritivores and therefore a shallowing of their size spectral slopes. Although H3 was not supported by the results, we did find a lowering of the size spectra of predators at higher trawling effort, suggesting that the abundance of all predators regardless of size is reduced by trawling. There was no evidence of release of predation pressure on large detritivores, as these also decreased in abundance with trawling effort. There was, however, an increase in the abundance of small detritivores, which can be indicative of a decrease in predation or a decrease in competition with large detritivores. The coupled model of Blanchard et al. (2009) predicted that fishing causes strongest declines in large predators, in turn releasing detritivores from predation pressure. The model did not include the direct and well-documented effect of bottom trawling on benthic invertebrates, which removes around $10 \%$ of fauna in a trawl pass depending on the gear and habitat (Sciberras et al. 2018), decreasing abundance of long-lived biota by $37 \%$ on a typical fishing ground (Hiddink et al. 2019). An obvious reason for the lack of an increase in the abundance of large detritivores is, therefore, that the direct negative effect of bottom trawling is larger than the positive effect of predator release. Smaller detritivores did increase in abundance in response to bottom trawling, and this can be explained by a combination of several factors: a release of predation pressure due to removal of predators by trawling (van Denderen et al. 2013); a release from competition with large detritivores due to removal by trawling; and a higher population growth rate that results in a smaller effect of a similar level of fishing mortality (Hiddink et al. 2019). An increase in abundance of small and short-lived fauna in response to trawling is often assumed in modelling studies (Hiddink et al. 2008; van Denderen et al. 2013), but so far empirical evidence for such an increase has been sparse (Hiddink et al. 2019; Jennings et al. 2002c). The conclusion that predation reduces the abundance of large detritivores (H1) may seem to contradict the conclusion that removing predators through trawling does not result in an increase in the abundance of large detritivores (H3). This is not a contradiction, though, as explained above. The direct effect of bottom trawling on detritivores outweighs the indirect effect through removal of their predators.

In summary, this is the first study to compare the size spectra of different functional groups across interacting gradients of trawling pressure and primary production. Our results highlight the importance of predator-detritivore interactions for the dynamics of benthic food webs. Overall, some of our results agree with the coupled model predictions of Blanchard et al. (2009), while some results do not match those predictions. Some of these discrepancies seem to be because the direct effects of trawling on detritivores were not included in the coupled model, and this can easily be modified. The reasons for other differences between the empirical data and model predictions (the lack of slope difference between detritivores and predators of small sizes, and the lack of effect of PP on slopes) are less obvious and more fundamental, as they relate to how the processes of growth and mortality were modelled by Blanchard et al. (2009). These discrepancies suggest that the use of a shared resource by detritivores, rather than a size-structured resource by predators, does not necessarily result in different size spectral slopes. Mechanisms that could explain such deviations are, for example, less efficient feeding by large detritivores compared with smaller ones or a larger predator/prey body mass ratio than expected for predators (Jennings et al. 2002a). Performing separate analyses for detritivores that are commonly preyed upon and for detritivores that are largely inedible may also provide further insights (van Denderen et al. 2013). The findings highlight the interactive effects different stressors have on marine ecosystems, which need to be understood if an ecosystem approach to managing the effects of exploitation and climate change on marine ecosystems is to be effective.

\section{Data accessibility}

Data used in this paper are archived in the British Oceanographic Data Centre under doi:10.5285/674d4224-7cc5-4080-e0536c86abc0626e (Howarth et al. 2018a).

\section{Acknowledgements}

This work was supported by the Natural Environment Research Council and Department for Environment, Food and Rural Affairs (grant No. NE/L003279/1, Marine Ecosystems Research Programme). PJS acknowledges support from Natural Environment Research Council through its National Capability Long-term Single Centre Science Programme, Climate Linked Atlantic Sector Science, grant No. NE/R015953/1. We thank Ian Pritchard, Wendy Robertson, Tanya Riley, Maria Giulia Moretti-Bushin, Jack Buckingham, Hannah Hernon, Charlotte Mathews, Claude Eric-Marquet, Craig Robertson, Marija Sciberras, Kathryn Hughes, Sowmiya Shivaji, Tom Perkins, Michael Spence, James Pilkington, Julia Rulent, Anna Canning, Gillian Peacock, Pascal Dubois, Anna Krystali, Nikki Lacey, Federico Ghiazza, Lucy Hawkesworth, Sarah Holmes, Sarah 
Dashfield, Christine Pascoe, Natalie Welden, Marine Cendrier, and Camille Govoue-Maurin for their assistance with sampling and laboratory work.

\section{References}

Behrenfeld, M.J., O’Malley, R.T., Siegel, D.A., McClain, C.R., Sarmiento, J.L., Feldman, G.C., et al. 2006. Climate-driven trends in contemporary ocean productivity. Nature, 444: 752-755. doi:10.1038/nature05317. PMID:17151666.

Behrenfeld, M.J., O’Malley, R.T., Boss, E.S., Westberry, T.K., Graff, J.R., Halsey, K.H., et al. 2016. Revaluating ocean warming impacts on global phytoplankton. Nat. Clim. Change, 6: 323-330. doi:10.1038/nclimate2838.

Blanchard, J.L., Jennings, S., Law, R., Castle, M.D., McCloghrie, P., Rochet, M.J., and Benoît, E. 2009. How does abundance scale with body size in coupled size-structured food webs? J. Anim. Ecol. 78: 270-280. doi:10.1111/j.1365-2656. 2008.01466.x. PMID:19120607.

Blanchard, J.L., Heneghan, R.F., Everett, J.D., Trebilco, R., and Richardson, A.J. 2017. From Bacteria to Whales: Using Functional Size Spectra to Model Marine Ecosystems. Trends Ecol. Evol. 32: 174-186. doi:10.1016/j.tree.2016.12.003. PMID:28109686.

Branch, G.M. 1984. Competition between marine organisms: Ecological and evolutionary implications. Oceanogr. Mar. Biol. Ann. Rev. 22: 429-593.

Cohen, J.E., Pimm, S.L., Yodzis, P., and Saldaña, J. 1993. Body sizes of animal predators and animal prey in food webs. J. Anim. Ecol. 62: 67-78. doi:10.2307| 5483.

Crain, C.M., Kroeker, K., and Halpern, B.S. 2008. Interactive and cumulative effects of multiple human stressors in marine systems. Ecol. Lett. 11: 13041315. doi:10.1111/j.1461-0248.2008.01253.x. PMID:19046359.

Daan, N., Gislason, H., Pope, J.G., and Rice, J.C. 2005. Changes in the North Sea fish community: evidence of indirect effects of fishing? ICES J. Mar. Sci. 62: 177-188. doi:10.1016/j.icesjms.2004.08.020.

Eigaard, O.R., Bastardie, F., Hintzen, N.T., Buhl-Mortensen, L., Buhl-Mortensen, P., Catarino, R., et al. 2017. The footprint of bottom trawling in European waters: distribution, intensity and seabed integrity. ICES J. Mar. Sci. 74: 847-865. doi:10.1093/icesjms/fsw194.

Elton, C. 1927. Chapter VII: Time and animal communities. In Animal Ecology. The Macmillan Company, New York. pp. 83-100.

European Environment Agency. 2015. Europe coastline shapefile [online]. Available from https://www.eea.europa.eu/data-and-maps/data/eea-coastline-foranalysis-1/gis-data/europe-coastline-shapefile.

Fu, C., Travers-Trolet, M., Velez, L., Grüss, A., Bundy, A., Shannon, L.J., et al. 2018. Risky business: the combined effects of fishing and changes in primary productivity on fish communities. Ecol. Model. 368: 265-276. doi:10.1016/j. ecolmodel.2017.12.003.

Gómez-Canchong, P., Blanco, J.M., and Quiñones, R.A. 2013. On the use of biomass size spectra linear adjustments to design ecosystem indicators. Sci. Marina, 77: 257-268. doi:10.3989/scimar.03708.22A.

Hiddink, J.G., Rijnsdorp, A.D., and Piet, G. 2008. Can bottom trawling disturbance increase food production for a commercial fish species? Can. J. Fish. Aquat. Sci. 65: 1393-1401. doi:10.1139/F08-064.

Hiddink, J.G., Jennings, S., Sciberras, M., Szostek, C.L., Hughes, K.M., Ellis, N., et al. 2017. Global analysis of depletion and recovery of seabed biota following bottom trawling disturbance. Proc. Natl. Acad. Sci. U.S.A. 114: 8301-8306. doi:10.1073/pnas.1618858114. PMID:28716926.

Hiddink, J.G., Jennings, S., Sciberras, M., Bolam, S.G., Cambiè, G., McConnaughey, R.A., et al. 2019. Assessing bottom-trawling impacts based on the longevity of benthic invertebrates. J. Appl. Ecol. 56: 1075-1083. doi:10.1111/ 1365-2664.13278.

Howarth, L.M., Somerfield, P., Blanchard, J., and Hiddink, J.G. 2018a. Celtic and Irish Sea benthic biomass size spectra data, September 2015 and April 2016. British Oceanographic Data Centre - Natural Environment Research Council, UK. doi:10/cmcg.

Howarth, L.M., Waggitt, J.J., Bolam, S.G., Eggleton, J., Somerfield, P.J., and Hiddink, J.G. 2018b. Effects of bottom trawling and primary production on the biological traits composition of benthic assemblages. Mar. Ecol. Prog. Ser. 602: 31-48. doi:10.3354/meps12690.

Jennings, S., and Blanchard, J.L. 2004. Fish abundance with no fishing: predic- tions based on macroecological theory. J. Anim. Ecol. 73: 632-642. doi:10.1111/ j.0021-8790.2004.00839.x.

Jennings, S., and Mackinson, S. 2003. Abundance-body mass relationships in size-structured food webs. Ecol. Lett. 6: 971-974. doi:10.1046/j.1461-0248.2003. 00529.x

Jennings, S., Pinnegar, J.K., Polunin, N.V.C., and Warr, K.J. 2001. Impacts of trawling disturbance on the trophic structure of benthic invertebrate communities. Mar. Ecol. Prog. Ser. 213: 127-142. doi:10.3354/meps213127.

Jennings, S., Warr, K.J., and Mackinson, S. 2002a. Use of size-based production and stable isotope analyses to predict trophic transfer efficiencies and predatorprey body mass ratios in food webs. Mar. Ecol. Prog. Ser. 240: 11-20. doi:10.3354/ meps240011.

Jennings, S., Pinnegar, J.K., Polunin, N.V.C., and Warr, K.J. 2002b. Linking sizebased and trophic analyses of benthic community structure. Mar. Ecol. Prog. Ser. 226: 77-85. doi:10.3354/meps226077.

Jennings, S., Nicholson, M.D., Dinmore, T.A., and Lancaster, J. 2002c. The effect of chronic trawling disturbance on the production of infaunal communities. Mar. Ecol. Prog. Ser. 243: 251-260. doi:10.3354/meps243251.

Law, R., Plank, M.J., James, A., and Blanchard, J.L. 2009. Size-spectra dynamics from stochastic predation and growth of individuals. Ecology, 90: 802-811. doi:10.1890/07-1900.1. PMID:19341149.

Lotze, H.K., Lenihan, H.S., Bourque, B.J., Bradbury, R.H., Cooke, R.G., Kay, M.C., et al. 2006. Depletion, degradation, and recovery potential of estuaries and coastal seas. Science, 312: 1806-1809. doi:10.1126/science.1128035. PMID: 16794081.

Macpherson, E., Gordoa, A., and Garcia-Rubies, A. 2002. Biomass size spectra in littoral fishes in protected and unprotected areas in the NW Mediterranean. Estuarine, Coastal and Shelf Science, 55: 777-788. doi:10.1006/ecss.2001.0939.

Nilssen, E.M., Larsen, R.B., and Hopkins, C.C.E. 1986. Catch and size-selection of Pandalus borealis in a bottom trawl and implications for population dynamics analyses. ICES CM, 4: 12 .

Poloczanska, E.S., Brown, C.J., Sydeman, W.J., Kiessling, W., Schoeman, D.S., Moore, P.J., et al. 2013. Global imprint of climate change on marine life. Nat. Clim. Change, 3: 919-925. doi:10.1038/nclimate1958.

Queirós, A.M., Hiddink, J.G., Kaiser, M.J., and Hinz, H. 2006. The effects of chronic bottom trawling disturbance on biomass, production and size spectra of invertebrate infauna communities from different habitats. J. Exp. Mar. Biol. Ecol. 335: 91-103. doi:10.1016/j.jembe.2006.03.001.

R Development Core Team. 2011. R: A language and environment for statistical computing [online]. R Foundation for Statistical Computing, Vienna, Austria. Available from http://www.R-project.org/.

Robinson, J.P.W., Baum, J.K., and Giacomini, H. 2016. Trophic roles determine coral reef fish community size structure. Can. J. Fish. Aquat. Sci. 73: 496-505. doi:10.1139/cjfas-2015-0178.

Sciberras, M., Hiddink, J.G., Jennings, S., Szostek, C.L., Hughes, K.M., Kneafsey, B., et al. 2018. Response of benthic fauna to experimental bottom fishing: a global meta-analysis. Fish Fish. 19: 698-715. doi:10.1111/faf.12283.

Sheldon, R.W., and Kerr, S.R. 1972. The population density of monsters in Loch Ness. Limnol. Oceanogr. 17: 796-798. doi:10.4319/1o.1972.17.5.0796.

Sprules, W.G., and Munawar, M. 1986. Plankton size spectra in relation to ecosystem productivity, size, and perturbation. Can. J. Fish. Aquat. Sci. 43: 17891794. doi:10.1139/f86-222.

Sprules, W.G., Barth, L.E., and Giacomini, H. 2016. Surfing the biomass size spectrum: some remarks on history, theory, and application. Can. J. Fish. Aquat. Sci. 73: 477-495. doi:10.1139/cjfas-2015-0115.

van Denderen, P.D., van Kooten, T., and Rijnsdorp, A.D. 2013. When does fishing lead to more fish? Community consequences of bottom trawl fisheries in demersal food webs. Proc. Biol. Sci. 280: 20131883. doi:10.1098/rspb.2013.1883. PMID:24004941.

Wilson, W.H. 1990. Competition and Predation in Marine Soft-Sediment Communities. Annu. Rev. Ecol. Syst. 21: 221-241. doi:10.1146/annurev.es.21.110190. 001253.

Wood, S. 2015. Package 'mgcv'. Mixed GAM Computation Vehicle with GCV/AIC/ REML Smoothness Estimation. Version 1.8-6. 